\title{
Simple forms and fluctuations of the line of sight: Implications for motor theories of form processing*
}

\author{
BRIAN J. MURPHY, GENEVIEVE M. HADDAD, and ROBERT M. STEINMAN $†$ \\ University of Maryland, College Park, Maryland 20742
}

\begin{abstract}
A contact lens optical lever was used to measure two-dimensional fixation characteristics when experienced Ss fixated at various positions within simple forms small enough to fall entirely on the foveal floor $(<80 \mathrm{~min})$. Fixation stability and the average direction of the line of sight were not markedly or systematically affected by the shape of the fixation stimulus. Similar results were obtained when all saccades were suppressed and the line of sight maintained exclusively by means of slow control. These results cast doubt on motor theories of form perception.
\end{abstract}

Eye movements or tendencies toward eye movements have been proposed as the explanatory principle in motor theories of visual illusions and form perception for more than a century (Lotze, 1852; Wundt, 1910; Hebb, 1949; Festinger, 1971). According to these theories, visual perception of form is based on the pattern of oculomotor responses or, more recently, the programming of these responses. The particular eye-movement pattern is determined by the shape of the retinal stimulus. Similarly, illusions are explained by reference to tendencies to eye movements that produce an incongruity between the pattern of oculomotor responses made or programmed and the pattern of retinal stimulation. Despite theorizing and much speculation, very little is actually known about the relationship between fine-grain characteristics of the human oculomotor pattern and the configuration of a visually presented stimulus. Detailed study of this relationship is essential not only for an evaluation of motor theories of form processing but also for complete descriptions of human oculomotor characteristics. The present experiments examine this relationship.

\section{METHOD}

\section{Eye-Movement Recording and Analysis}

An electronic contact-lens optical lever was used to make continuous two-dimensional recordings of eye position. A detailed

* This research was supported by Grant NEI 00325 and a NSF traineeship awarded to Brian J. Murphy. Please address reprint requests to the first author.

tWe thank Harry Blum for insights and suggestions that guided our choice of stimuli, for his help with their computer generation, and for valuable suggestions throughout the course of the research; Martin J. Kelly, Jr., John Z Levinson, and Charles E. Sternheim for critical comments on the manuscript; and Lawrence Fryor for his help with the evaluation of the granular properties of our diffusing screen. We also thank F. Frome, C. Jablonski, E. Kowler, K. Larsen, P. McGrath, J. Matthews, S. Murphy, B. Winterson. and $M$. Wise for technical assistance. Many of these results were reported at the 1973 meeting of the Association for Research in Vision and Ophthalmology. description of the apparatus has been reported by Haddad and Steinman (1973). As used in the present experiments, the recording limits of this instrument were $1 \mathrm{deg}$ of arc on both meridians, permitting resolution of eye position to approximately $3 \mathrm{sec}$ of arc. For each trial, the mean and standard deviation of eye position voltages on the horizontal and vertical meridians were calculated on-line by a spccial-purpose analog device. The time constants of the integrating citcuits in this device were chosen empirically such that means and standard deviations estimated by the device from a random sample of fixation trials for each $\mathrm{S}$ matched, to within $1 \%$, means and standard deviations calculated from a random sample of brief eye-position voltages taken from the same trials. The output of the analog device was digitized and printed out at the end of each trial.

\section{Stimuli}

The stimuli were high-contrast $(>90 \%)$ photographic transparencies of computer-generated and drawn forms. The transparencies were shown in rear projection on a diffusing screen (Callier's coefficient $=4,6$ ) that had no visible texture at the viewing distance of $2 \mathrm{~m}$. A pellicle was placed in the S's line of sight so that a projected form and a small well-focused oscilloscope point $(<2$ min of arc) could be superimposed. The $S$ could position the

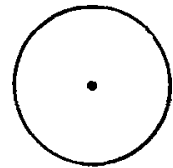

$7 \theta^{\prime}$

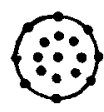

$39^{\prime}$

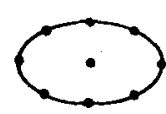

$78^{\prime} \times 39^{\prime}$

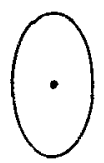

$39^{\prime} \times 7 \theta^{\prime}$
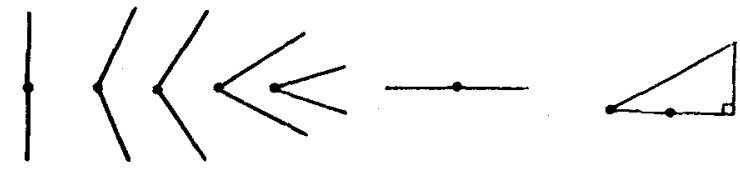

$80^{\prime}$

$132^{\circ} 4115^{\circ} 40^{\circ} \times 324$

$80^{\prime}$

$30^{\circ} 4,60^{\circ} 4,90^{\circ} 4$

Fig. 1. The stimuli (shapes) and fixation positions (filled circles) used in the present experiments. Each point represent one of the fixation positions studied. Ss fixated either one of the specified regions within each of the forms or a small point in the same physical position in the absence of the form. 
point in any region either within or on the boundary of the form. The point and line drawings of the forms were equally bright. Both were viewed through a red (Wratten No. 25) filter, permitting effective foveal stimulation with low levels of light $(9.3 \mathrm{~mL})$. These conditions made it possible for trials to be run in complete darkness without any extraneous visual cues or persistent afterimages.

Drawings of the forms and fixation positions are shown in Fig. 1. These positions were chosen to test the effect of shape attributes such as size, asymmetry, orientation, degree of curvature, and angularity on control of eye position. All forms subtended less than 80 min of are at the S's eye and were, therefore, small enough to be contined to the floor of the fovea (Polyak, 1941, p. 198) where acuity is good. This allowed the form to be seen clearly without the necd tor seanning saceades.

\section{Procedure}

Before the start of each block of trials, the $S$ positioned the point at one of the specitied locations either within or on the boundary of the form being viewed. Alternating 5-sec control and experimental trials were then run. In the control trials, the form was removed and the $S$ was asked to maintain a steady line of sight on the point. In the experimental trials, the form was visible and the $S$ was, once again, asked to maintain a steady line of sight on the point. However, when he started the trial, the point disappeared and he was required to maintain his line of sight in the same position with only the form in view.

\section{Subjects}

Both Ss, G.H. and R.S., had served in numerous fixation studies employing the optical lever recording technique, were accustomed to wearing tight-fitting scleral contact lenses, and knew the purpose of the present experiment. The stimuli were seen by the right cye-the left eye was closed and covered, and head movements were restrained by an acrylic dental bite plate.

\section{RESULTS}

\section{Fixation is Not Influenced by the Shape of a Visual Display}

Variability of the line of sight during maintained fixation at well-defined (e.g., the vertex of a 30-deg angle) or estimated (e.g., the midpoint of a radius of a circle) positions within a variety of simple geometric forms was not greater than during fixation of points in the same physical positions in the absence of the forms. Differences in mean standard deviations of eye position between fixation of forms and fixation of points were, on the average, less than $1 \mathrm{~min}$ of arc. The largest difference was only $2.4 \mathrm{~min}$ of arc for S G.H. and $2.1 \mathrm{~min}$ of arc for S R.S. For both Ss, the range of mean standard deviations was virtually the same with the forms as it was with the points. These results are summarized in Tables 1 and 2 .

These data show that fluctuations of the line of sight during maintained fixation are not influenced by

Table 1

Inverse Fixation Stability of Subject G. H. Maintaining Fixation at Selected Positions Within a Variety of Forms (Form) or at a Point in the Same Physical Position in the Absence of the Form (Point)

\begin{tabular}{|c|c|c|c|c|c|c|c|c|}
\hline \multirow[b]{2}{*}{ Stimulus Conditions } & \multicolumn{3}{|c|}{ Horizontal Meridian } & \multicolumn{3}{|c|}{ Vertical Meridian } & \multicolumn{2}{|c|}{ Trials } \\
\hline & Form & Point & $\Delta$ & Form & Point & $\Delta$ & $\mathbf{N}_{\mathrm{F}}$ & $N_{p}$ \\
\hline Circle $(78 \mathrm{~min})$ Center & $7.4(0.0)$ & $7.4(0.0)$ & 0.0 & $6.1(0.0)$ & $6.1(0.0)$ & 0.0 & 8 & 9 \\
\hline \multicolumn{8}{|l|}{ Edges: } & 39 \\
\hline Horizontal & $3.2(0.9)$ & $3.4(1.1)$ & -0.2 & $2.8(0.5)$ & $2.8(0.6)$ & 0.0 & 30 & 32 \\
\hline Vertical & $3.6(0.9)$ & $3.2(0.7)$ & 0.4 & $2.9(0.7)$ & $3.1(1.1)$ & -0.2 & 29 & 30 \\
\hline Right Oblique & $3.5(1.1)$ & $3.3(0.7)$ & 0.2 & $3.3(0.9)$ & $3.3(0.8)$ & 0.0 & 31 & 31 \\
\hline Left Oblique & $3.7(1.2)$ & $3.6(1.3)$ & 0.1 & $3.4(1.1)$ & 3.1 (1.1) & 0.3 & 30 & 33 \\
\hline \multicolumn{9}{|l|}{ Halfway to Edge: } \\
\hline Horizontal & $4.2(1.5)$ & $3.0(0.8)$ & 1.2 & $3.2(0.9)$ & $3.0(0.7)$ & 0.2 & 30 & 33 \\
\hline Vertical & $3.9(1.3)$ & $2.9(0.5)$ & 1.0 & $2.7(0.7)$ & $2.7(0.6)$ & 0.0 & 29 & 31 \\
\hline Right Oblique & $3.7(1.1)$ & $3.2(0.5)$ & 0.5 & $3.8(1.8)$ & $3.7(1.3)$ & 0.1 & 30 & 32 \\
\hline Left Oblique & $3.6(1.4)$ & $3.0(0.7)$ & 0.6 & $3.2(1.1)$ & $3.5(0.8)$ & -0.3 & 29 & 33 \\
\hline Vertical Ellipse $(78 \times 39 \mathrm{~min})$ Center & $4.6(1.5)$ & $2.5(0.7)$ & 2.1 & $3.2(1.1)$ & $3.1(0.8)$ & 0.1 & 31 & 31 \\
\hline $\begin{array}{l}\text { Horizontal Ellipse ( } 39 \times 78 \mathrm{~min} \text { ) Center } \\
\text { Edges: }\end{array}$ & \multicolumn{5}{|c|}{ Edges: } & -0.3 & 29 & 30 \\
\hline Horizontal & $4.0(1.3)$ & $3.5(0.8)$ & 0.5 & $2.7(0.8)$ & $2.9(0.9)$ & -0.2 & 33 & 35 \\
\hline Vertical & $4.1(1.4)$ & $3.2(0.7)$ & 0.9 & $2.9(0.8)$ & $2.9(0.6)$ & 0.0 & 30 & 30 \\
\hline Oblique & $4.0(1.6)$ & $3.0(1.4)$ & 1.0 & $2.9(0.9)$ & $2.9(1.3)$ & 0.0 & 57 & 59 \\
\hline Horizontal Line ( $78 \mathrm{~min})$ Center & $5.4(1.6)$ & $3.5(1.1)$ & 1.9 & $3.0(0.7)$ & $2.9(0.6)$ & 0.1 & 35 & 33 \\
\hline Vertical Line $(78 \mathrm{~min})$ Center & $3.7(0.6)$ & $4.1(0.8)$ & -0.4 & $4.8(1.1)$ & $4.0(1.0)$ & 0.8 & 31 & 33 \\
\hline 115-deg Angle at Vertex & $5.1(1.2)$ & $4.4(0.9)$ & 0.7 & $4.4(1.2)$ & $3.9(0.7)$ & 0.5 & 36 & 36 \\
\hline 70-deg Angle at Vertex & $2.9(0.6)$ & $2.6(0.6)$ & 0.3 & $2.0(0.4)$ & $2.3(0.4)$ & -0.3 & 32 & 32 \\
\hline 32-deg Angle at Vertex & $3.7(1.4)$ & $2.9(0.8)$ & 0.8 & $2.2(0.5)$ & $2.6(0.8)$ & -0.4 & 32 & 33 \\
\hline \multicolumn{9}{|l|}{ Triangle } \\
\hline $\begin{array}{l}\text { at } 30 \text {-deg Corner } \\
\text { Center of Line Between }\end{array}$ & $3.7(0.8)$ & $3.3(0.6)$ & 0.4 & $3.4(1.0)$ & $3.8(0.9)$ & -0.4 & 30 & 30 \\
\hline 30- and 90-deg Angles & $4.1(1.7)$ & $3.4(0.8)$ & 0.7 & $3.2(1.0)$ & $4.1(1.2)$ & -0.9 & 30 & 30 \\
\hline
\end{tabular}

Note-Inverse fixation stability is summarized as mean standard deviations in minutes of arc on horizontal and vertical meridians. The difference $(\Delta)$ in mean standard deviations $\left(\overline{S D}_{F^{+}}-\overline{S D}_{P}\right)$ is shown, as is the number of form $\left(N_{F}\right)$ and point $\left(N_{P}\right)$ trials run. The $S D s$ of the SDs are given in parentheses. 
Table 2

Inverse Fixation Stability of Subject R.S. Maintaining Fixation at Selected Positions Within a Variety of Forms (Form) or at a Point in the Same Physical Position in the Absence of the Form (Point)

\begin{tabular}{|c|c|c|c|c|c|c|c|c|}
\hline \multirow[b]{2}{*}{ Stimulus Conditions } & \multicolumn{3}{|c|}{ Horizontal Meridian } & \multicolumn{3}{|c|}{ Vertical Meridian } & \multicolumn{2}{|c|}{ Trials } \\
\hline & Form & Point & $\Delta$ & Form & Point & $\Delta$ & $\mathrm{N}_{\mathrm{F}}$ & $\mathrm{N}_{p}$ \\
\hline Circle $(78 \mathrm{~min})$ Center & $4.3(1.3)$ & $4.6(1.3)$ & -0.3 & $2.8(0.8)$ & $3.3(0.9)$ & -0.5 & 29 & 29 \\
\hline Circle $(39 \mathrm{~min})$ Center & $3.6(1.3)$ & $4.5(1.7)$ & -0.9 & $2.6(1.1)$ & $3.3(1.1)$ & -0.7 & 32 & 29 \\
\hline \multicolumn{9}{|l|}{ Edges: } \\
\hline Horizontal & $4.6(2.0)$ & $2.5(0.6)$ & 2.1 & $4.7(1.7)$ & $3.4(1.2)$ & 1.3 & 31 & 33 \\
\hline Vertical & $3.8(0.8)$ & $4.2(1.6)$ & -0.4 & $2.8(0.8)$ & $3.5(1.2)$ & -0.7 & 32 & 32 \\
\hline Right Oblique & $4.9(1.9)$ & $5.0(2.0)$ & -0.1 & $2.6(0.9)$ & $3.7(1.2)$ & -0.3 & 35 & 31 \\
\hline Left Oblique & $4.2(1.4)$ & $4.2(1.3)$ & 0.0 & $2.4(0.8)$ & $3.5(1.1)$ & -1.1 & 30 & 31 \\
\hline \multicolumn{9}{|l|}{ Halfway to Edge: } \\
\hline Horizontal & $3.4(1.5)$ & $4.1(1.9)$ & -0.7 & $2.0(1.5)$ & $3.4(1.3)$ & -1.4 & 30 & 31 \\
\hline Vertical & $3.1(1.1)$ & $4.1(1.6)$ & -1.0 & $2.3(0.8)$ & $3.2(1.2)$ & -0.9 & 32 & 34 \\
\hline Right Oblique & $3.4(1.5)$ & $3.9(1.7)$ & -0.5 & $2.1(1.5)$ & $3.0(1.1)$ & -0.9 & 32 & 32 \\
\hline Left Oblique & $3.3(1.2)$ & $3.9(1.3)$ & -0.6 & $2.1(1.2)$ & $3.2(1.1)$ & -1.1 & 31 & 31 \\
\hline Vertical Ellipse $(78 \times 39 \mathrm{~min})$ Center & $4.0(1.1)$ & $4.4(1.6)$ & -0.4 & $3.1(1.2)$ & $3.7(0.9)$ & -0.6 & 31 & 31 \\
\hline Horizontal Ellipse $(39 \times 78 \mathrm{~min})$ Center & $4.3(1.4)$ & $4.3(1.4)$ & 0.0 & $2.8(0.6)$ & $3.3(0.8)$ & -0.5 & 36 & 42 \\
\hline \multicolumn{9}{|l|}{ Edges: } \\
\hline Vertical & $4.2(1.4)$ & $5.0(2.0)$ & $\begin{array}{l}-0.0 \\
-0.8\end{array}$ & $\begin{array}{l}3.0(0.8) \\
3.1(1.2)\end{array}$ & $\begin{array}{ll}3.7 & (1.4) \\
4.1(1.3)\end{array}$ & $\begin{array}{l}-0.7 \\
-1.0\end{array}$ & $\begin{array}{l}28 \\
33\end{array}$ & 32 \\
\hline Oblique & $4.3(1.5)$ & $5.4(2.2)$ & -1.1 & $3.7(1.5)$ & $5.0(1.6)$ & -1.3 & 57 & 47 \\
\hline Horizontal Line ( $78 \mathrm{~min})$ Center & $5.0(1.6)$ & $5.8(2.6)$ & -0.8 & $3.9(0.8)$ & $5.6(1.6)$ & -1.7 & 27 & 27 \\
\hline Vertical Line $(78 \mathrm{~min})$ Center & $4.2(1.4)$ & $5.3(2.1)$ & -1.1 & $3.9(0.9)$ & $4.6(1.4)$ & -0.7 & 25 & 25 \\
\hline 132-deg Angle at Vertex & $5.7(1.7)$ & $6.1(2.2)$ & -0.4 & $4.3(1.2)$ & $5.0(1.2)$ & -0.7 & 22 & 24 \\
\hline 70-deg Angle at Vertex & $4.7(2.0)$ & $4.8(2.0)$ & -0.1 & $3.4(1.2)$ & $3.9(1.5)$ & -0.5 & 27 & 28 \\
\hline 32-deg Angle at Vertex & $3.9(0.8)$ & $4.4(1.1)$ & -0.5 & $3.1(0.8)$ & $3.3(0.8)$ & -0.2 & 27 & 26 \\
\hline \multicolumn{9}{|l|}{ Triangle } \\
\hline at 30 deg Corner & $4.5(1.5)$ & $5.1(1.7)$ & -0.6 & $2.8(0.7)$ & $3.8(0.7)$ & -1.0 & 26 & 26 \\
\hline $\begin{array}{l}\text { Center of Line Between } \\
30-\text { and } 90 \text {-deg Angles }\end{array}$ & $3.7(1.0)$ & $4.5(1.4)$ & -0.7 & $2.6(0.5)$ & $4.5(1.2)$ & -1.9 & 25 & 25 \\
\hline
\end{tabular}

Note-Inverse fixation stability is summarized as mean standard deviations in minutes of arc on horizontal and yertical meridians. The difference $(\Delta)$ in mean standard deviations $\left(\overline{S D}_{F}-\overline{S D}_{P}\right)$ is shown, as is the number of form $\left(N_{F}\right)$ and point $\left(N_{P}\right)$ trials run. The $S D s$ of the SDs are given in parentheses.

the contiguration of visually presented stimuli, at least when these stimuli are confined to the floor of the fovea and their luminance and spectral composition make them photopically effective. Foveal forms are excellent fixation targets even when their retinal stimulation is asymmetric with respect to the line of sight and even when the visual error signal used to keep the eye in place is generated by contours falling as much as 40 min of arc away from the center of the foveal bouquet. The failure to find effects of shape on the variability of the line of sight did not arise from an insufficient number of observations: there were 1,357 trials for S R.S. and 1,463 trials for S G.H.

The average direction of the line of sight during maintained fixation is also not influenced by the shape of a visual display. Evidence for this is of two kinds. First, the Ss' eye movements were monitored continuously on a two-dimensional display that was sufficiently large for eye movements as small as $1 \mathrm{~min}$ of arc to be easily detected. Systematic shifts of the average direction of the line of sight toward a preferred region either within the forms or on their boundaries were not observed. Second, these qualitative observations were confirmed by an analysis of mean eye positions based on a sample of suitable trials drawn from several stimulus conditions. The

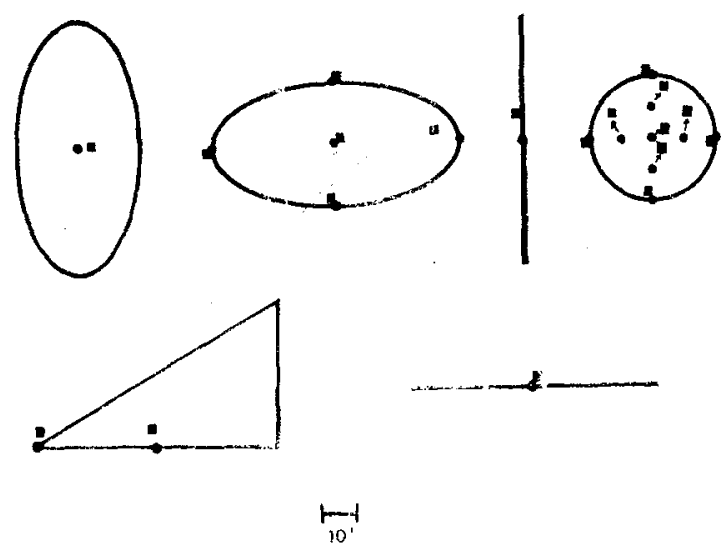

Fig. 2. Average direction of S G.H.'s line of sight during maintained fixation within forms (filled squares) relative to the specified fixation positions (filled circles). Arrows connect the corresponding symbols in those instances where the correspondence might be ambiguous. 


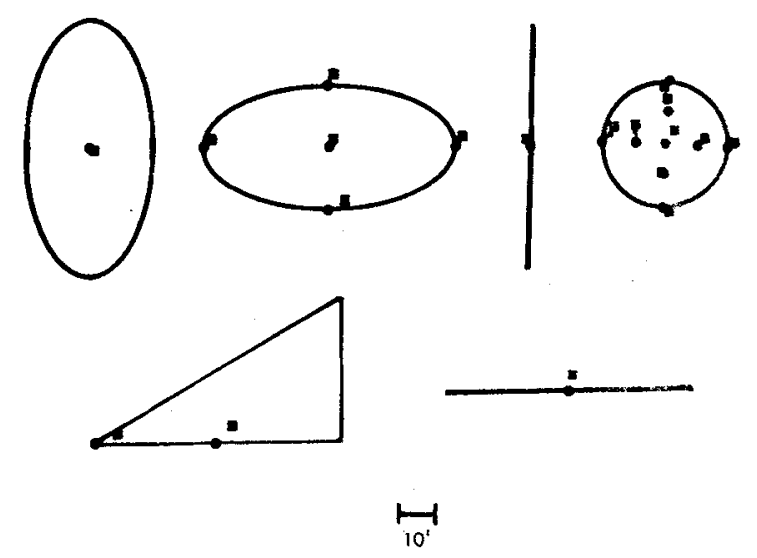

Fig. 3. Average direction of $S$ R.S.'s line of sight during maintained fixation within forms (filled squares) relative to the specified fixation positions (filled circles). Arrows connect the corresponding symbols in those instances where the correspondence might be ambiguous.

mean eye position on trials in which the $S$ fixated a form were compared to the average of the mean eye positions of the preceding and following trial in which the $S$ fixated a point at the same physical position. This comparison was made only if the difference between the two trials in which the $S$ fixated the point was less than $4 \mathrm{~min}$ of arc on both meridians. This criterion was chosen on the basis of Steinman's (1965) measurements, which showed that deviations in mean eye position of this magnitude are to be expected when sources of variability due to stimulus parameters are removed. This permitted 203 comparisons to be made for S G.H. and 139 for S R.S. for the conditions shown. For a given stimulus condition, the average of the mean eye positions on acceptable trials in which the $S$ fixated the point was defined as the "on-target" position for that condition. The difference between this "on-target" position and the average of the mean eye positions on the corresponding trials in which the $S$ fixated a form is a measure of the influence of the form on the average direction of the line of sight. Figures 2 and 3 summarize the results of this analysis.

Neither S showed any tendency for his line of sight to be displaced toward a preferred region, either within the forms or on their boundaries. This lack of stimulus influence is easily seen when one compares displacements of mean eye position during fixation of the center of the vertical line, horizontal line, or base of the triangle. Although each $S$ displayed individuality, his performance during fixation at these positions was virtually the same regardless of the orientation of the line or its relationship to connecting lines. It did not make any difference whether the line stood alone or was part of a closed form. Most of the deviations in mean eye position shown in these figures were small. The overall mean vector magnitude for the shifts of the direction of the line of sight was $3.6 \mathrm{~min}$ of are for S R.S. and $4.4 \mathrm{~min}$ of arc for S G.H. Shifts of the average direction of the line of sight of this magnitude would be expected even if the fixation stimulus were a diffraction-limited point (Steinman, 1965).

These data suggest that the direction of the line of sight during maintained fixation is not influenced by the configuration of a foveally effective stimulus. A possible explanation of this lack of influence could be suggested on the following grounds: Nachmias (1959, 1961) has shown that slow control (directed drift) is visually guided, and Steinman, Haddad, Skavenski, and Wyman (1973) have shown that microsaccades as small as 5 min of arc can be made voluntarily. Thus, it could be argued that the line of sight during fixation drifts to a preferred region of the stimulus and that these drifts are counteracted by diligent Ss using saccades to return their line of sight to the fixation positions they were instructed to maintain. Although the lack of systematic influence of shape attributes on either the variability or the average direction of the line of sight makes this argument unlikely, we tested this possibility directly.

\section{Slow Control is Not Influenced by the Shape of a Visual Display}

The original experiment was rerun, using one of the Ss and many of the same stimuli after the $S$ had been instructed not to make saccades. An electronic sensor sounded a tone whenever a saccade $1.3 \mathrm{~min}$ of arc or larger occurred. The rare trials $(5 \%)$ in which the $S$ inadvertently made a saccade were not included in the analysis.

The stimulus configuration did not have adverse effects on the stability of the line of sight, even when the $S$ did not make saccades. In fact, the average

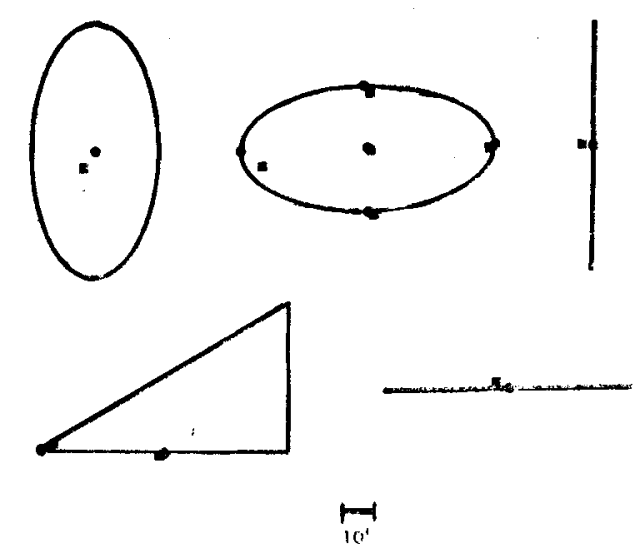

Fig. 4. Average direction of S R.S.'s line of sight when saccades were suppressed and slow control was used to maintain the line of sight within forms (filled squares) relative to the specified fixation positions (filled circles). Arrows connect the corresponding symbols in those instances where the correspondence might be ambiguous. 
Table 3

Inverse Fixation Stability of Subject R.S. Using Slow Control Exclusively to Hold His Eye at Selected Positions Within a Variety of Forms (Form) or at a Point in the Same Physical Position in the Absence of the Form (Point)

\begin{tabular}{|c|c|c|c|c|c|c|c|c|}
\hline \multirow[b]{2}{*}{ Stimulus Conditions } & \multicolumn{3}{|c|}{ Horizontal Meridian } & \multicolumn{3}{|c|}{ Vertical Meridian } & \multicolumn{2}{|c|}{ Trials } \\
\hline & Form & Point & $\Delta$ & Form & Point & $\Delta$ & $\mathrm{N}_{\mathrm{F}}$ & $\mathrm{N}_{\mathrm{P}}$ \\
\hline Circle $(78 \mathrm{~min})$ Center & $2.8(1.8)$ & $3.2(2.1)$ & -0.3 & $2.4(1.2)$ & $2.1(0.7)$ & 0.3 & 27 & 27 \\
\hline $\begin{array}{l}\text { Vertical Ellipse }(78 \times 39 \mathrm{~min}) \text { Center } \\
\text { Horizontal Ellipse }(39 \times 78 \mathrm{~min}) \text { Center } \\
\text { Edges: }\end{array}$ & $\begin{array}{l}3.8(1.9) \\
4.0(1.7)\end{array}$ & $\begin{array}{ll}4.1 & (2.0) \\
4.3 & (2.2)\end{array}$ & $\begin{array}{l}-0.3 \\
-0.3\end{array}$ & $\begin{array}{l}2.6(1.0) \\
2.2(0.9)\end{array}$ & $\begin{array}{l}2.8(1.7) \\
2.2(1.1)\end{array}$ & $\begin{array}{r}-0.2 \\
0.0\end{array}$ & $\begin{array}{l}29 \\
31\end{array}$ & $\begin{array}{l}29 \\
32\end{array}$ \\
\hline $\begin{array}{l}\text { Horizontal } \\
\text { Vertical } \\
\text { Oblique }\end{array}$ & $\begin{array}{ll}3.8 & (2.1) \\
4.0 & (2.7) \\
4.2 & (2.0)\end{array}$ & $\begin{array}{ll}4.1 & (2.3) \\
4.0 & (2.1) \\
3.6 & (1.2)\end{array}$ & $\begin{array}{r}-0.3 \\
0.0 \\
0.6\end{array}$ & $\begin{array}{ll}2.5 & (1.4) \\
3.1 & (1.8) \\
3.0 & (1.5)\end{array}$ & $\begin{array}{ll}2.8 & (1.7) \\
3.4 & (2.6) \\
3.7 & (2.0)\end{array}$ & $\begin{array}{l}-0.3 \\
-0.3 \\
-0.7\end{array}$ & $\begin{array}{l}33 \\
32 \\
44\end{array}$ & $\begin{array}{l}33 \\
34 \\
43\end{array}$ \\
\hline $\begin{array}{l}\text { Horizontal Line }(78 \mathrm{~min}) \text { Center } \\
\text { Vertical Line }(78 \mathrm{~min}) \text { Center } \\
\text { 132-deg Angle at Vertex } \\
\text { 70-deg Angle at Vertex } \\
\text { 32-deg Angle at Vertex } \\
\text { Triangle }\end{array}$ & $\begin{array}{ll}4.2 & (1.7) \\
3.7 & (2.1) \\
4.0 & (2.2) \\
4.8 & (2.9) \\
3.0 & (1.0)\end{array}$ & $\begin{array}{ll}3.9 & (2.2) \\
3.5 & (2.1) \\
4.2 & (2.1) \\
4.9 & (2.5) \\
3.1 & (1.7)\end{array}$ & $\begin{array}{r}0.3 \\
0.2 \\
-0.2 \\
-0.1 \\
-0.1\end{array}$ & $\begin{array}{l}2.6(1.1) \\
3.0(1.7) \\
2.5(1.0) \\
3.0(1.6) \\
2.3(0.7)\end{array}$ & $\begin{array}{ll}3.2 & (2.1) \\
2.7 & (1.8) \\
3.2 & (1.4) \\
2.7 & (1.3) \\
1.7 & (0.5)\end{array}$ & $\begin{array}{r}-0.6 \\
0.3 \\
-0.7 \\
0.3 \\
0.6\end{array}$ & $\begin{array}{l}27 \\
25 \\
25 \\
28 \\
28\end{array}$ & $\begin{array}{l}27 \\
25 \\
24 \\
28 \\
28\end{array}$ \\
\hline $\begin{array}{l}\text { at } 30 \text {-deg Corner } \\
\text { Center of Line Between } \\
30 \text { - and } 90 \text {-deg Angles }\end{array}$ & $\begin{array}{l}3.8(1.9) \\
2.6(1.5)\end{array}$ & $\begin{array}{l}2.6(1.4) \\
2.8(1.6)\end{array}$ & $\begin{array}{r}1.2 \\
-0.2\end{array}$ & $\begin{array}{l}1.8(0.6) \\
1.7(0.7)\end{array}$ & $1.8(0.9)$ & 0.0 & 30 & 31 \\
\hline
\end{tabular}

Note-Inverse fixation stability is summarized as mean standard deviations in minutes of arc on horizontal and vertical meridians. The difference $(\triangle)$ in mean standard deviations $\left(\overline{S D}_{F}-\overline{S D}_{P}\right)$ is shown, as is the number of form $\left(N_{F}\right)$ and point $\left(N_{P}\right)$ trial runs. The $S D s$ of the $S D s$ are given in parentheses.

variability of the line of sight using slow control to keep the eye in place was only $4 / 5$ of what it was during normal fixation. Standard deviations of eye position ranged from 2 to $5 \mathrm{~min}$ of arc for both the forms and the points. The largest difference was only $1.2 \mathrm{~min}$ of are on the horizontal meridian and $0.7 \mathrm{~min}$ of arc on the vertical meridian. These results are summarized in Table 3.

The average direction of the line of sight was not influenced by the shape of the stimulus, even when saccades were suppressed and slow control was used to maintain eye position. Figure 4 shows the average direction of the line of sight at several positions within a number of forms as well as the average direction of the line of sight when the $S$ saw only a point in the same positions in space. The criterion for the selection of trials and the analysis of the data were the same as those used when the $S$ was asked to maintain fixation. The line of sight was not drawn toward any region that can be related to the nature of the stimulus. As was the case in the fixation experiment, all of the shifts were small. The overall mean vector magnitude was only 3.3 min of arc.

The lack of any systematic tendency for the line of sight to be drawn to some preferred region of the stimulus cannot be ascribed to the presence of extraneous visual stimuli. The point or form were the only sources of retinal information used by the $S$ s in the maintenance of their lines of sight. Our confidence in this stems from two sources. First, the Ss reported that no stray light or extraneous visual stimuli were visible during the recording sessions. Second, a series of trials was run in which all lighting and recording conditions were identical to those of the present experiments. The forms were not visible, and the $S$ was asked to maintain a steady line of sight on the point using only slow control. One second after the start of the trial, the point was removed and the S's eye rapidly drifted away. This result shows that there were no extraneous visual stimuli because this is precisely what is to be expected when one attempts to maintain a steady eye position without saccades in the absence of visual information (Skavenski \& Steinman, 1970).

There is one subjective observation worth noting at this point. Throughout the course of the experiments, neither $S$ observed any distortion of the shape of the visual stimuli. Since both $S s$ were experienced psychophysical observers and paid careful attention to the appearance of the stimuli, we believe that there are no first-order effects of the oculomotor pattern on the appearance of simple forms. We cannot rule out the possibility that the pattern of eye movements might have some influence on the results of an experiment explicitly designed to test shape discrimination. But, it seems unlikely that its contribution would be sufficient to alter the appearance of foveally presented forms whose functionally important shape characteristics were seen clearly without any directed visual search.

\section{DISCUSSION}

\section{Shape Explained by Eye Movements}

In their most radical form, motor theories of visual illusion and form perception have held that the eye is 
drawn from place to place by properties of the visual stimulus and that perception is founded on the sensations that accompany these eye movements (Wundt, 1910). These overt motor theories gained some experimental support when Delabarre (1897) measured eye movements during the scanning of the Mueller-Lyer illusion and found that eye movements were larger on the perceptually long side of the illusion than on the perceptually short side. However, several years later, Judd (1905) raised a serious objection to the adequacy of the overt motor theory on two grounds. First, the magnitude of the illusion did not correlate well with the magnitude of the errors in the eye movements made during the scanning from apex to apex of the illusion. Second, the overshoots and undershoots made during scanning were inmediately followed by compensatory eye movements that corrected these errors. Sensations accompanying these compensatory eye movements hould have cancelled the perceptual error caused by the initially incorrect eye novement suggested as the basis of the illusion in the first place. Judd's doubts were confirmed by Lewis (1908), who clearly demonstrated the inefficacy of the overt motor theories by showing that the Mueller-Lyer illusion is obtained with tachistoscopic presentation which precluded the possibitity of eye movements.

Hebb (1949) revived motor theory by suggesting that implicit, as well as executed, eye movements play an integral role in perception of shape. More recently, Festinger (1971) has gove even further in this vein by proposing a completely covert motor theory to explain visual perception of shape and illusions of extent. Festinger's "efferent readiness" theory is a development of Lotze's (1852) theory of local signs, bringing it in line with current knowledge/ and speculation about human oculomotor physiology. Lotze proposed that our perception of spatial relations derives from the conscious awareness of the eye movements that would be necessary to bring any point of retinal stimulation to the center of the fovea. On the grounds that saccades are the only eye movements that provide position information, Festinger has proposed that our visual perception of shape is determined by the set of programs for saccadic eye movements that are available for immediate use. The programs are placed in readiness by the visual input. Therefore, "visual input corresponding to a curve on the retina would bring into readiness the efferent prograns that, if issued, would direct the eye to fixate any part of that contour [Festinger, 1971, p. 267]." Thus, efferent readiness theory circumvents the difticulty of overt motor theory by linking perception to the programming of, rather than the execution of, eye movements. Although the theory does not require eye movement as a necessarv condition for perception, it does predict that any eye movements that do occur are manifestations of the programs that presumably serve as the basis of visual form perception.

This prediction is not supported by the results of the present experiments because no similarity was found between the pattern of retinal stimulation and the pattern of eye movements. This lack of correspondence questions the explanatory adequacy of motor theories of visual perception, whether they be overt or covert.

\section{Eye Movements Explained by Shape}

Although our results do not show any isomorphic relationship between the pattern of eye movements and the pattern of retinal stimulation as is predicted by motor theories of form processing, eye movements could be influenced by the shape of a visual stimulus if the stimulus available to the oculomotor system was some transformation of the retinal stimulus or the perceived form. The present experiments were motivated in part by this possibility and our choice of stimuli and fixation positions were based on Blum's (1973) recent analysis of shape. Blum developed a simple shape transformation, based on natural biological processes, that could be responsible for the processing of visual shape information. This transformation (symmetric function) consists of the locus of all points whose minimum distance to the boundary exists to more than one point on the boundary (symmetric axis) and their associated distances to the boundary (symmetric distances). For any convex closed form, these points all lie within the form. For example, the symmetric ax is of an ellipse is the straight line connecting the two centers of curvature of ellipse points that lie on the major axis of the ellipse. The symmetric axis of a circle consists of one symmetric point at the center of the circle.

The possibility that the oculomotor system is constrained by such a transformation was suggested by Richards and Kaufman (1969), who based this suggestion on their prior finding that naive Ss show a centering tendency in their spontaneous behavior during maintained fixation (Kaufman \& Richards, 1969). However, our results with experienced Ss, instructed to maintain their lines of sight in a specitied region within a variety of forms, show that the line of sight is not forced to move in any particular manner that can be predicted by the stimulus configuration or where the line of sight is placed within the configuration. This is true regardless of whether the $\mathrm{S}$ uses saccades (voluntary oculomotor acts) or slow control (reflexive oculomotor responses) to keep the eye in the specified place. The tendency of naive $S$ s to maintain fixation at the center of gravity of simple forms may arise from attentional preferences because our results show that the oculomotor system 
is not constrained by shape when the $E$ rather than the $S$ chooses the fixation direction.

Researchers in visual science are often concerned with where their observer's eye is aimed at the time that they make their measurements and provide fixation aids at the risk of introducing extraneous visual information that can influence their experimental results (Jameson \& Hurvich, 1967). The results of the present experiments show that the stability of the line of sight of a committed and experienced $S$ will be neither markedly nor systematically influenced by the shape of a foveally presented stimulus. This means that observers can establish and maintain fixation for several seconds at estimated positions within asymmetric as well as symmetric displays without need for extraneous details to guide the line of sight. As long as there is foveal input, special fixation aids are not needed to position and maintain the orientation of the eye.

The present results are not the only findings that show that the line of sight is not constrained by the parameters of a fixated stimulus. Steinman (1965) showed that its size, color, and luminance had only negligible influences on fixation stability when targets were photopically effective and contined to the foveal floor. Rattle (1968) and Boyce (1967) confirmed and extended these findings to larger fixation targets and higher luminance levels. These and the present results show that when the visual stimulus is foveally effective, the ability to choose and maintain the direction of the line of sight is not influenced in significant ways by physical properties of the stimulus that cause objects in the physical world to have shape, color, and brightness.

This kind of an arrangement has obvious advantages to a foveate animal. He can look at what he wants, he can look where he wants, he can stay in an area expecting something to appear, or worrying about something that may appear without having his line of sight disturbed by properties of the visual input that simply help him to decide which region of his visual world he desires to watch.

\section{REFERENCES}

BuUm, H. Biological shape and visual science (Part 1). Journal of Theoretical Biology, 1973, 38, 205-287.

Boyce, P. R. The effect of change of target field luminance and colour on fixation eye movements. Optica Acta, 1967, 14, 213-217.

DelabarRe, E. B. A method of recording eye movements. American Journal of Psychology, 1897, 9, 572-574.

Festinger, L. In P. Bach-Y-Rita and C. C. Collins (Eds.), The control of eye movements. London: Academic Press, 1971.

Haddad, G. M., \& Steinman, R. M. The smallest voluntary saccade: Implications for fixation. Vision Research, 1973, 13, 1075-1086.

HEBB, D. O. The organization of behavior. New York: Wiley, 1949. Pp. 44-50.

JAMESON, D., \& HuRvich, L. Fixation-light bias: An unwanted by-product of fixation control. Vision Research, 1967, 7, 805-809.

JudD, C. H. Müller-Lyer illusion. Psychological Review Monograph Supplement, 1905, 7, 55-81.

KaUfMaN, L., \& Richards, W. Spontaneous fixation tendencies for visual forms. Perception \& Psychophysics, 1969, 5, 85-88.

Lewis, E. O. The effect of practice on the perception of the Müller-Lyer illusion. British Journal of Psychology, 1908, 2, 294-306.

Lotze, R. H. Medicinische Psychologie. (1852) ReprintedAmsterdam: Bonet, 1966.

NaChmias, J. Two-dimensional motion of the retinal image during monocular fixation. Journal of the Optical Society of America, $1959,49,902-908$.

Nachmias, J. Determiners of drift of the eye during monocular fixation. Journal of the Optical Society of America, 1961, 51, $761-766$.

Polyax, S. L. The retina. Chicago: The University of Chicago Press, 1941.

RATTLE, J. D. Effect of target size on monocular fixation. Optica Acta, 1969, 16, 183-192.

Richards, W., \& Kaufman, L. "Center-of-gravity" tendencies for fixations and flow patterns. Perception \& Psychophysics, $1969,5,81-84$.

Skavenski, A., \& Steinman, R. M. Control of eye position in the dark. Vision Research, 1970, 10, 193-203.

Steinman, R. M. Effect of target size, luminance, and color on monocular fixation. Joumal of the Optical Society of America, 1965, 55, 1158-1165.

Steinman, R. M., Haddad, G. M., Skavenski, A. A., \& Wyman, D. Miniature eye movement. Science, 1973, 181, 810-819.

WundT, W. Grundzüge der physiologischen Psychologie. Vol. 2. (5th ed.) Leipzig: Engelmann, 1910.

(Received for publication January 24, 1974; revision received July 21,1974 .) 